\title{
INFLUENCE OF MAGNESIUM ON THE STATE OF THE CARDIOVASCULAR SYSTEM IN CHILDREN WITH CHRONIC TONSILITIS
}

DOI: 10.36740/WLek202005112

\author{
Oleksandr I. Smiyan' ', Yuliia A. Man'ko', Andrii M. Loboda' ', Sergii V. Popov', Igor YU. Vysots'kyy', \\ Victoria 0. Petrashenko', Igor M. Martsovenko², Kateryna 0. Smiian', Valentina A. Plakhuta', \\ Volodymyr M. Serhiyenko', Olena. L. Ovsyanko', Tatiana 0. Aleksakhina', Al-Rawashdeh Bara' \\ 'SUMY STATE UNIVERSITY INSTITUTE, SUMY, UKRAINE \\ 2MUNICIPAL NON-COMMERCIAL ENTERPRISE "SUMY REGIONAL CLINICAL CARDIOLOGY DISPENSARY", SUMY, UKRAINE
}

\begin{abstract}
The aim of the study was to evaluate the condition of the cardiovascular system and the effect of the combined preparation of magnesium and vitamin B6 in children with secondary cardiomyopathy on the background of chronic tonsillitis.

Materials and methods: 100 children at the aged of 13-17 years were surveyed, including 60 patients with secondary cardiomyopathy with chronic tonsillitis. And the group I consisted of 45 children receiving standard treatment, group II - 15 patients who, along with standard treatment, received the drug magnesium. The control group consisted of 40 healthy children. To assess the condition of the cardiovascular system and vegetative regulation, we performed electrocardiographic examination (ECG), exercise test and ECG control, cardiointervalography with clinoortostatic test. The concentration of magnesium in the serum was determined by atomic absorption spectrophotometry. Also, we have provided the requirements of the principles of bioethics and drafted a protocol in accordance with the basic principles of the Helsinki Declaration.

Results: In addition to the standard treatment of children with magnesium drug, there was a significant decrease in the frequency of sinus arrhythmias, disorders of the intraventricular conduction, and the processes of repolarization, extrasystole, sinus suchchardia were not observed in any of the patients. The normalization of magnesium in the serum of patients was observed.

Conclusions: Supplementation of combination therapy with magnesium and B6 helped to improve myocardial electrophysiology and cardiac output, as well as to normalize the serum magnesium in children with secondary cardiomyopathy.
\end{abstract}

KEY WORDS: children, chronic tonsillitis, cardiovascular system, magnesium

Wiad Lek. 2020;73(5):904-908

\section{INTRODUCTION}

Chronic tonsillitis is one of the most common diseases in pediatric practice. The incidence of chronic tonsillitis in children under the age of three is $2-3 \%$, and up to 12 years - up to $12-15 \%[1,2]$.

This problem is extremely urgent due to the increase in both local and systemic tonsillogenic lesions. At present, there are about a hundred diseases associated with chronic tonsillitis. The lack of effect from the treatment and aggravation of disorders by the organs and systems, probably due to the fact that doctors do not consider chronic tonsillitis as a cause of certain pathological conditions $[1,3]$.

Non-inflammatory heart lesions of childhood tonsillogenic origin are often characterized by a long asymptomatic course. There are no clinical pathognomonic signs of this pathology in the initial period. Early symptoms are usually masked by a clinical picture of the underlying disease. Therefore, the need for timely diagnosis of secondary cardiac lesions against chronic tonsillitis in children is the most important preventive measure to prevent the disease from progressing in the future $[3,4,5]$.
Changes in the cardiovascular system in children with chronic tonsillitis due to the action of neuro-reflex, bacteriemic, toxinemic and allergic factors. In addition, in the emergence and progression of pathology of the myocardium of the tonsilogenesis origin, disturbances of micro- and macro-elemental metabolism play an important role. The role of individual minerals in the functioning of the cardiovascular system is still being studied. However, changes in micro- and macro-elemental status in children with chronic tonsillitis and their influence on the development of cardiovascular disorders in this category of patients are not sufficiently elucidated $[4,6,7]$.

Among the deficiencies of macro- and trace elements, magnesium deficiency is a leader, especially in children and adolescents. Recent years studies have shown that a significant magnesium deficiency occurs in $33.6-42.5 \%$ of children over 13, while in children under 4 years old it is $12 \%, 5-11$ years $-28 \%$. This is probably due to the increased need for this macronutrient in adolescence, impaired absorption against the background of dysbiotic processes, 
as well as modern processing technologies for foods that reduce their magnesium content $[8,9,10]$.

It should be noted that pyridoxine is important to ensure metabolic processes in the myocardium, metabolism of amino acids, carbohydrates and fats, and to maintain the functioning of the child's immune system. In addition, it has neurotropic, hematopoietic, cardiotropic and hepatotropic effects $[11,12]$.

When using a combination of magnesium and pyridoxine synergism in the manifestation of pharmacological activity, increases the rate of absorption of magnesium in the intestine, improves its transmembrane penetration into cells due to the formation of the chelate complex vitamin B6-magnesium-amino acid, increases concentration with urine $[7,13,14]$.

\section{THE AIM}

Therefore, in view of the above, the aim of our study was to evaluate the condition of the cardiovascular system and the effect of the combined preparation of magnesium and vitamin B6 in children with secondary cardiomyopathy on the background of chronic tonsillitis.

\section{MATERIALS AND METHODS}

It was examined 100 children at the aged of 13-17 years, including 60 patients with secondary cardiomyopathy with chronic tonsillitis who were inpatient at Sumy Children's Clinical Hospital. The control group consisted of 40 healthy children of the same age and sex. All sick children were divided into two groups: group I was 45 children with secondary cardiomyopathy who received standard treatment according to the current protocols of the Ministry of Health, group II - 15 patients with secondary cardiomyopathy who, along with the standard treatment received magnesium drug, administered 1 dose tablet 3 times a day from the 2 nd to 3 rd day of hospitalization for 12 days. A combination of magnesium and vitamin B6 containing magnesium lactate dihydrate $(470 \mathrm{mg})$ and pyridoxine hydrochloride $(5 \mathrm{mg})$ was administered.

Assessment of cardiovascular status was performed on days 1-2 of hospitalization and on days 12-14 of treatment. The electrical activity of the heart was evaluated by the results of electrocardiographic examination (ECG) in 12 standard leads according to the traditional method. To study the functional and reserve capabilities of the cardiovascular system, to detect its preclinical changes in children with chronic tonsillitis, a sample with physical activity and ECG control (Martine sample) was used. The condition of the autonomic nervous system was evaluated using the method of cardiointervalography with a clinoortostatic test. The concentration of magnesium in the serum was determined by atomic absorption spectrophotometry. Statistical processing of the results was carried out using the standard statistical computer system Microsoft Excel (2007) adapted for biomedical research. This study was approved by the ethics committee of the Sumy state Uni- versity, Sumy, Ukraine. All procedures were carried out in accordance with the ethical standards of the responsible committee on human experimentation and with the Helsinki Declaration of 1975, as revised in 2000.

\section{RESULTS}

An analysis of the anamnesis of life revealed that in children with non-inflammatory lesions of the cardiovascular system on the background of chronic tonsillitis revealed the following factors, which were observed significantly more often than in the control group, namely: pathology of pregnancy, perinatal pathology, the age of parents over 35 years, birth weight less than $2800 \mathrm{~g}$, early artificial feeding, cardiovascular disease of parents. In addition, it was found that among patients with secondary cardiomyopathy on the background of chronic tonsillitis, there were significantly more frequent recurrent SARS and more than two childhood infections in the anamnesis, as opposed to almost healthy children $(\mathrm{p}<0.05)$. These factors can have a negative effect on the course of chronic tonsillitis, and lead to cardiac complications of tonsillogenic origin. In the course of the study, it was found that secondary cardiomyopathies of tonsillogenic genesis were more often associated with one factor - in $(45.00 \pm 6.48) \%$ of patients, two in (26.67 $\pm 5.76) \%$ of children, and three in $(6,67 \pm 3.25) \%$.

During the exercise with physical exertion in children with secondary cardiopathy significant disorders of hemodynamics were revealed, manifested by reduced (threshold) reaction to physical activity in $(68,33 \pm 6,06) \%$ of cases, unsatisfactory - in $(21,67 \pm 5,36) \%(\mathrm{p}<0.05)$, in contrast to the data of the group of healthy children $(\mathrm{p}<0.05),(61.67 \pm$ $6.33) \%$ of patients had hypertensive type of hemodynamic reaction, whereas in the majority of children control group observed normotonic type of hemodynamics. It should be noted that ECG changes were recorded in all patients with tonsillogenic heart disease, which was significantly higher than in virtually healthy children. Thus, impaired repolarization in children with secondary cardiomyopathy was (81.67 $\pm 5.04) \%$, ventricular extrasystoles - $(18.33 \pm 5.04) \%$, and the recovery period of changes in cardiac dynamics in patients in this study group lasted up to five minutes or more ((73.02 $\pm 5.64) \%$ ), whereas normally does not exceed 3 minutes.

Thus, in most children with secondary cardiopathy on the background of chronic tonsillitis, the exercise response was reduced, mainly as a result of the hypertensive type of hemodynamic reaction with impaired ECG repolarization and prolongation of the recovery period, which may indicate hypoxemia and worsening as well as reducing the cardiovascular system's backup and functionality.

In the analysis of vegetative homeostasis in children with secondary cardiomyopathy, it was found that patients had changes in autonomic reactivity in the form of a decrease in the variational span $(\Delta \mathrm{X})$, increase in the amplitude of the fashion (AMO) and autonomic tone.

Thus, in children with tonsillogenic cardiopathy, there was a significant increase in AMO $((27.1 \pm 0.90) \%)$ versus $((18.15 \pm 0.74) \%)$ in the control group with a simultaneous 
decrease in $\Delta \mathrm{X}((0.20 \pm 0,01) \mathrm{c})$ against $((0,30 \pm 0,01) \mathrm{s}$ in the group of healthy children $(\mathrm{p}<0,05)$, which indicates an increase in the effects of the sympathetic link of the ANS and a decrease in vagal influences on the cardiac activity with the preserved sinus activity nodes, as indicated by the absence of the difference of the Mo $(0.73 \pm 0.02) \mathrm{s}$ versus $(0.72 \pm 0.01) \mathrm{s}$ in the control $(\mathrm{p}>0.05)$.

As a result of conducting a clinoortostatic test it was established that in patients with secondary cardiopathy the initial autonomic tone (IN1) was $(112,2 \pm 5,7)$ mind. units, ascending (standing) (IN2) - $(219,4 \pm 14,2) \mathrm{d}$. units, in almost healthy children - $(67,0 \pm 0,33)$ mind. units and $(90.6 \pm 4.00) \mathrm{dm}$. units such a significant increase ( $\mathrm{p}$ $<0.05$ ) of autonomic tone in children with tonsillogenic cardiac pathology is due to the pronounced tension of the regulatory mechanisms of the body at rest and under load. Vegetative reactivity in patients with cardiopathy in children was hypersympathetic. Thus, according to CIG data, it is established that children suffering from tonsillogenic cardiopathy have decreased parasympathetic effects and increased activity of sympathoadrenal effects, and thus, hypersympathetic tonic autonomic reactivity takes place, which indicates the tension of the compensatory mechanisms in the regulation of cardiac activity and autonomic disorders in children with chronic tonsillitis. Such mechanisms of regulation are imperfect, potentiating overtension and disruption of adaptation processes, which may be important in the further development and intensification of secondary disorders of the cardiovascular system in children against chronic tonsillitis $[1,6,15]$.

Analysis of the dynamics of cardiac activity, depending on the therapy, showed that gradual recovery of electrocardiographic parameters occurs in patients of both I and II groups. However, supplementation with magnesium drug contributed to a significant normalization of cardiovascular status compared with pre-treatment and group I data.

Thus, after carrying out standard treatment in children of group I the frequency of violations of intraventricular conduction was significantly reduced to $(8,89 \pm 4,29) \%$ (p $<0,05$ ), which did not differ from the data of the control group ( $p>0,05)$. On day 12-14 of standard therapy, sinus arrhythmias were found in significantly fewer patients ((33.33 $\pm 7.11) \%)(\mathrm{p}<0.05)$ compared to pre-treatment data, but the frequency with which they were observed, remained significantly higher than in virtually healthy individuals. The incidence of electrocardiographic changes such as early ventricular repolarization syndrome, blockage, and sinus arrhythmias in group I patients was closer to that of the control group. However, against the background of standard treatment, the incidence of repolarization disorders, migrations of the supraventricular rhythm driver, and extrasystoles was almost unchanged compared to pre-treatment data and differed from the values of children without pathology.

In the group of patients with secondary cardiomyopathy with the introduction of the drug magnesium there was a positive effect on the electrophysiology of myocardium and there was a significant normalization of indicators of cardiac activity. Thus, on the 12-14th day of treatment in children of group II there was a significant decrease in the frequency of sinus arrhythmias $((20,00 \pm 10,69) \%)$, disorders of the intraventricular conduction $((6,67 \pm 6,67) \%)$ $(\mathrm{g}<0,05)$, and the processes of repolarization, extrasystole, sinus suchchardia were not observed in any of the patients. After treatment with magnesium, the number of patients who had blockages, syndrome of early repolarization of the ventricles, migration of supraventricular rhythm driver did not differ significantly from the values in the control group.

As a result of determining the magnesium content in the serum of patients with secondary cardiomyopathy in children in the first days of therapy, a significant decrease in the level of this macronutrient was found to $(0.79 \pm 0.05)$ $\mathrm{mmol} / \mathrm{l}$, in contrast to the values of the control group $(1.13 \pm 0,08) \mathrm{mmol} / \mathrm{l}(\mathrm{p}<0.05)$. After standard treatment in patients in group $\mathrm{I}$, the concentration of magnesium remained significantly low $((0.88 \pm 0.03) \mathrm{mmol} / \mathrm{l})(\mathrm{p}>$ 0.05 ) and differed from the values of persons without pathology. In addition, the addition of standard therapy with magnesium-containing drug contributed to a significant normalization of magnesium in patients in group II, which was $(1.21 \pm 0.11) \mathrm{mmol} / \mathrm{l}(\mathrm{p}<0.05)$.

Therefore, patients with secondary cardiomyopathy revealed hypomagnesemia, possibly requiring supplementation of magnesium drug therapy.

These changes can affect the metabolic processes in the heart, because magnesium is one of the important elements that ensures the normal functioning of myocardial cells.

Thus, the instrumental studies of the cardiovascular system in children with chronic tonsillitis, allows to establish early signs of cardiac disorders, the level of reserve and functionality of the cardiovascular system, which is important in timely detection of tonsilogenic cardiac lesions, the appointment of effective therapy and preventing the progression of dystrophic changes in the myocardium. The use of a magnesium-containing drug will increase the effectiveness of the treatment of children with non-inflammatory tonsillogenic heart disease by normalizing metabolic processes and reducing the myocardium and, thus, improve the course of these diseases and the quality of life of patients.

\section{DISCUSSION}

It should be noted that more than $80 \%$ of the surveyed children had 3 or more signs of cardiac dysfunction according to ECG, which confirms the presence of secondary cardiomyopathy according to various authors $[3,4,11]$.

Carrying out a CIG with a clinoortostatic breakdown in patients showed tension of regulatory mechanisms and hypersympathetic tonic autonomic reactivity in the form of a decrease in the variational span $(\Delta \mathrm{X})$, an increase in the amplitude of the mode (AMO) and the autonomic tone. The revealed changes in cardiac activity indicate vegetative shifts, hypoxia and dysmetabolic processes in the myocardium of patients with non-inflammatory tonsillogenic lesions of the cardiovascular system $[4,11]$. 
As a result of our studies, a decrease in the serum magnesium level in children with secondary cardiopathy was found on the background of chronic tonsillitis.

Given the results of studies by authors such as Marushko Yu. V. (2016), Gromova OA (2014), the identified disorders can affect the metabolism of the heart, since magnesium is an important element for the normal functioning of myocardial cells. In addition, a decrease in serum magnesium in children with secondary cardiomyopathy of tonsillogenic origin may be associated with impaired absorption in the intestine against the background of dysbiotic processes in patients $[6,8]$.

According to other authors, magnesium deficiency has also been found to be a factor in the development of cardiovascular diseases, such as hypertension and cardiac arrhythmias $[8,9]$.

When studying the effect of the combined preparation of magnesium and pyridoxine, its positive effect on the cardiovascular system of children with chronic tonsillitis was established. Not only it was the normalization of magnesium content in the serum, but also the improvement of myocardial electrophysiology according to electrocardiography (reduction of the frequency of sinus arrhythmias and disorders of the intraventricular conduction, absence after treatment of disorders of repolarization, extrasystoles and sinus). Marushko Yu.V. et al. (2016) found a positive effect of combination magnesium in children with hypertension and vascular dysfunction [6].

Other authors in their studies have studied the effect of magnesium sulfate to relieve the attack of ventricular tachycardia in hereditary syndrome of prolongation of the interval $\mathrm{Q}-\mathrm{T}$. Thus, a rapid effect of the preparation of magnesium in various forms of heart rhythm arrhythmias was revealed $[2,8,14]$.

\section{CONCLUSIONS}

1. In patients with secondary cardiomyopathy on the background of chronic tonsillitis, ECG changes were recorded in the form of sinus arrhythmias, impaired intraventricular conduction and repolarization, sinus tachycardia, syndrome of early repolarization of the ventricles of the ventricles, myocardial infarction .

2. In most children with secondary cardiopathy, the response to exercise has been reduced, mainly as a result of the hypertensive type of hemodynamic reaction with impaired ECG repolarization and prolongation of the recovery period.

3. According to the data of cardiointervalography with a wedge-orthostatic test in children with secondary cardiomyopathy, an increase of autonomic tone and predominance of sympathicotonic autonomic reactivity were revealed.

4. As a result of determination of the magnesium macronutrient content in the serum of patients with secondary cardiomyopathy in children in the first days of therapy, a significant decrease in magnesium level to $(0.79 \pm 0.05)$ mmol / l was found, unlike the values of the group of almost healthy children.
5. Supplementation of combination therapy with magnesium and B6 has contributed to the improvement of myocardial electrophysiology and cardiac performance, as well as the normalization of the magnesium in the serum of children with secondary cardiomyopathy on the background of chronic tonsillitis.

Study prospects: More research is needed to answer such important questions as: ideal dose, onset time, and duration of magnesium intake, as well as the type and method of administration of this macronutrient.

\section{REFERENCES}

1. Ruzhentsova T. Kardiomiopatii u detej [Cardiomyopathy in children]. Medical Council. 2014; 6:66-69. (Ru).

2. Marushko Y., Marushko T., Gischak T. [Diahnostyka ta udoskonalennia likuvannia vtorynnoi kardiomiopatii u ditei [Diagnosis and improvement of secondary cardiomyopathy in children]. Children's doctor. 2014;2(53):11-24. (Ua).

3. Marushko Y. Rol ta mistse defitsytu mahniiu v rozvytku vehetosudynnoi dysfunktsii u ditei [The role of this deficiency in the development of vegetative dysfunction in children]. Child health. 2016;4(72):43-48. (Ua).

4. Popovich V. Khronichnyi tonzylit ta poiednani z nym somatychni zakhvoriuvannia [Chronic tonsillitis and related somatic diseases]. Medical Nature. 2014;1(17):74-82. (Ua).

5. Gromov 0., Torshin I., Yudina N. Deficzit magniya i narusheniya regulyaczii tonusa sosudov [Magnesium deficiency and impaired regulation of vascular tone]. Cardiology. 2014;7:66-72. (Ru).

6. Martinov A., Urlaeva I. and Akatova E. Znachenie deficzita magniya v kardiologii [The Importance of Magnesium Deficiency in Cardiology]. Concillium medicum. 2014;1:43-46. (Ru).

7. Chernatska 0., Demikhova N. Improvement of treatment in person with arterial hypertension and type 2 diabetes mellitus. Georgian Medical News. 2018;11(284):47-51.

8. Syrkin A., Salagaev G., Syrkina E. et al. Preimushhestva orotata magniya dlya korrekczii magnij-deficzitny 'kh sostoyanij u bol'ny'kh $s$ razlichny mi formami narushenij ritma serdcza [Advantages of magnesium orotate for correction of magnesium deficiency in patients with various heart rhythm disturbances]. Cardiology and Cardiovascular surgery. 2019;12(4):308. (Ru).

9. Vdovichenko V., GoncharukV., KorshakT. Bronskaya G. Preparaty` kaliya/ magniya: raczional 'ny`e osnovy` primeneniya $v$ klinike [Potassium / magnesium preparations: rational use in the clinic]. Medical news. 2016;11:8-10. (Ru).

10. KaravaevP,VeklichA.,KoziolovaN.Diabeticheskayakardiomiopatiya:osobennosti serdechno-sosudistogo remodelirovaniya [Cardiovascular remodeling in patients with diabeticcardiomyopathy]. Russian Journal ofCardiology.2019;24 (11):42-47. (Ru).

11. Altintas M. Prevalence of atopy in children with hypertrophic tonsil and recurrent/chronic tonsillitis. International Medical Journal. 2019;8(3):732.

12. Doyle L., Anderson P., Lee K. Antenatal Magnesium Sulfate and Outcomes for School-aged Children-Reply. JAMA. 2015;313(3):306.

13. Darmaputri S., Wiguna T. Evidence based case report: Pyridoxine supplementation in children with pervasive developmental disorders. Paediatrica Indonesiana. 2014;54(3):186.

14. Zaakouk A., Hassan M., Tolba 0 . Serum magnesium status among obese children and adolescents. Egyptian Pediatric Association Gazette. 2016; 64(1):32-37. 
15. Chernatska 0., Demikhova N., Rudenko T. Assesment of the lipid profile correction in patients with arterial hypertension and type 2 diabetes mellitus. Azerbaijan Medical News. 2018;11(284):47-51.

The work is a fragment of the researchproject of peadiatric department Sumy State University "Regional peculiarities of health and incidence rates among children" (State Registration No. 0117U004937).

\section{ORCID and contributionship:}

Oleksandr I. Smiyan - 0000-0001-8225-0975 A

Yuliia A. Man'ko - 0000-0003-3348-2862 ${ }^{\mathrm{C}}$

Andrii M. Loboda - 0000-0002-5400-773X ${ }^{B}$

Sergii V. Popov - 0000-0002-1789-1474 ${ }^{D}$

Igor YU. Vysots'kyy - 0000-0002-6357-3362 ${ }^{\mathrm{B}}$

Victoria O. Petrashenko - 0000-0002-4648-8916 ${ }^{B}$

Igor M. Martsovenko - ${ }^{\mathrm{C}}$

Kateryna O. Smiian - 0000-0002-8030-6418 ${ }^{D}$

Valentina A. Plakhuta - 0000-0002-1206-2853 ${ }^{\mathrm{C}}$

Volodymyr M. Serhiyenko - ${ }^{E}$

Olena. L. Ovsyanko - ${ }^{D}$

Tatiana O. Aleksakhina - ${ }^{E}$

Al-Rawashdeh Bara - ${ }^{F}$

\section{Conflict of interest:}

The Authors declare no conflict of interest

\section{CORRESPONDING AUTOR \\ Oleksandr I. Smiyan \\ Pediatrics Department, Sumy State University \\ 1 Sanatorna str., Sumy, Ukraine \\ tel: +380506316005 \\ e-mail: smiyana@ukr.net}

Received: 23.01 .2020

Accepted: 27.03 .2020

A - Work concept and design, B - Data collection and analysis, C - Responsibility for statistical analysis, D-Writing the article, $\mathbf{E}$-Critical review, $\mathbf{F}$ - Final approval of the article 